\title{
The Thermal Performance of a Phenolic Resin Blend Modified by Silicone and Nano $\mathrm{Al}_{2} \mathrm{O}_{3}$
}

\author{
Yan Qin *, Yunxia Li, Zhilong Rao, Xi Zhang, Qilin Mei, Zhixiong Huang \\ Key Laboratory for Specially Functional Composites of Ministry of Education, School of Materials Science and Engineering, \\ Wuhan University of Technology, Luo-Shi road 122, 430070 Wuhan, China
}

\begin{abstract}
This paper adopts the melt blending method for organic silicon resin/nano $\mathrm{Al}_{2} \mathrm{O}_{3}$ and $\mathrm{PF}$. The organic silicon resin in the blending resin cures and forms interpenetrating network structures to improve the heat resistance of $P F$ plastics. TG, DSC and FESEM analysis characterize the changes in heat resistance of the blend-modified PF plastic. In addition, this article investigated the heat-resisting performance of resin composite, which is modified by nano $\mathrm{Al}_{2} \mathrm{O}_{3}$ as a coupling agent. FT-IR is used to explore the changes. The modified nano $\mathrm{Al}_{2} \mathrm{O}_{3}$ can improve the heat resistance of the composite materials effectively. When the temperature reaches $800{ }^{\circ} \mathrm{C}$, the residual rate of modified nano $\mathrm{Al}_{2} \mathrm{O}_{3}$ /silicone/PF composites is about $\mathbf{7 8 . 0 7 \%}$.
\end{abstract}

Keywords-PF; silicone; nano $\mathrm{Al}_{2} \mathrm{O}_{3}$; blend modified; thermal performance

\section{INTRODUCTION}

$\mathrm{PF}$ is early synthetic resins to achieve industrial production and is one of the three main thermosetting resins. In $1975^{[1]}$, it was first used in the field of refractory products. $\mathrm{PF}$ has wide raw material sources, low cost, simple synthetic process, excellent water resistance, aging resistance, good rigidity, good electric properties, dimensional stability and so on. However, without modification, PF has low heat resistance, poor oxidation resistance ability, large mass loss of high temperature aerobic ablation, high linear ablation rate, low mechanical strength under high temperature and a series of other disadvantages that limit its application in the field of refractory $^{[2]}$.

The concept of ceramfying organic polymers was first proposed in $1964^{[3]}$ and offers new ideas and new methods for the use of polymers. Adding some inorganic mineral filler and other auxiliaries to the organic polymer can form the ceramfying polymer-based composite materials. Among the achievements, Professor Y. B. Cheng at Monash University in Australia, found a series of ceramfying organic silicon-inorganic fillers composite materials, which have widespread application in the field of wire and cable manufacture ${ }^{[4-8]}$. At high temperature (about $1000^{\circ} \mathrm{C}$ ), $\mathrm{SiO}_{2}$ formed by the decomposition of organic silicon can achieve a complex eutectic reaction with mineral filler and form a new eutectic liquid. The liquid phase gradually diffuses and forms a kind of ceramic network. As it cools, its ceramic network is further strengthened. This kind of ceramic structure has excellent high temperature resistance and it can prevent the heat diffusing inside the material. Thus it can inhibit the material interior from quality loss offers refractory properties ${ }^{[9-11]}$.

Organic silicon resin has the main molecular chain $\mathrm{Si}-\mathrm{O}-\mathrm{Si}$ and side chain organic groups. It has concurrent excellent properties of both organic polymer and inorganic material, such as low surface tension, high temperature mechanical strength, excellent electrical insulating properties, low rate of combustion, no dripping phenomenon and no poisonous gas releasing during burning, and excellent fireproof performance ${ }^{[12-13]}$.

This paper mainly studied the blending modification of $\mathrm{PF}$ by silicone and nano $\mathrm{Al}_{2} \mathrm{O}_{3}$ using the silane oxygen groups in the molecular chain of organic silicon to get an alcoholizing reaction with PF in the phenolic hydroxyl. In addition, under high temperature, the silicone and PF crosslink upon curing across the molecular chain network incorporating the inorganic filler and forming interpenetrating network structure. When temperature is high, the organic silicon resin and inorganic filler can share the heat with PF to raise the heat resistance of the system as a whole.

\section{EXPERIMENT}

\section{A. Materials}

All materials were used as received. SAR-9 poly(methyl siloxane) from Shanghai Resin Company, China; PF(2101) from Changzhou Tianma Group Co., Ltd., China; 6-methyl tetramine, analytically pure from Beijing Chemical Reagent Factory, China; ethanol (Shanghai chemical industry Co., Ltd., China); $\alpha$ - nano $\mathrm{Al}_{2} \mathrm{O}_{3}$; glass material; and silane coupling agent $\mathrm{KH}$ - 550, analytically pure from Dow Corning corporation, Midland, MI, USA.

\section{B. Instrument}

All instruments were used as received. ZK - 82B vacuum drying oven from Experimental Instrument Factory in Shanghai, China; CL - 1A magnetic stirrer and KQ-C glass instrument air dryer from Gongyi City Instrument Co., Ltd., China; FD-101S collection hot type constant temperature heating magnetic stirrer from Shanghai East Seal refrigeration equipment Co., Ltd., China; Kde KQ 200 high power ultrasonic cleaners from Kunshan Ultrasonic Instruments Co., Ltd., China.

\section{Sample preparation}

We dissolved PF, SAR - 9 poly(methyl siloxane), and 6-methyl tetramine in ethanol. Ethanol volume was used to adjust the viscosity of mixture, which was stirred to achieve 
a uniform state, about $30 \mathrm{~min}$. The mixed system was heated at $80^{\circ} \mathrm{C}$ for $3 \mathrm{~h}$ to remove the solvent. This was cured at $180^{\circ} \mathrm{C}$ for $4 \mathrm{~h}$, then $200^{\circ} \mathrm{C}$ for $2 \mathrm{~h}$. Samples were removed and crushed for testing.

For processing of surface modification of nano $\mathrm{Al}_{2} \mathrm{O}_{3}$, we took nano $\mathrm{Al}_{2} \mathrm{O}_{3}, 3 \%$ of $\mathrm{KH}-550$ for nanoparticles in a beaker and added ethanol under stirring for $30 \mathrm{~min}$ and sonication for another $30 \mathrm{~min}$. The mixture was then heated and stirred for $4 \mathrm{~h}$. After washing with ethanol to remove excess coupling agent, we heated at $90^{\circ} \mathrm{C}$ for $12 \mathrm{~h}$.

\section{Characterization}

\section{1) Laser particle size analysis}

A Mastersizer 2000 laser particle size analyzer which was made in Malvern Instruments Ltd, UK was used to explore the particle size of nano $\mathrm{Al}_{2} \mathrm{O}_{3}$.

2) Thermal gravimetric analysis(TG)

TG analysis used a STA449c/3/G synchronous thermal analyzer under nitrogen at a flow rate of $15 \mathrm{ml} / \mathrm{min}$. The scanning range was from room temperature to $800^{\circ} \mathrm{C}$ at $10^{\circ} \mathrm{C} / \mathrm{min}$ to study the effect of organic silicone resin and nano $\mathrm{Al}_{2} \mathrm{O}_{3}$ on the high temperature retention rate of $\mathrm{PF}$.

3) Differential Scanning Calorimetric Analysis (DSC)

DSC analysis used a STA $449 \mathrm{c} / 3 / \mathrm{G}$ synchronous thermal analyzer under nitrogen at a flow rate of $15 \mathrm{ml} / \mathrm{min}$. The scanning range was from room temperature to $800^{\circ} \mathrm{C}$ at $10^{\circ} \mathrm{C} / \mathrm{min}$. The purpose is to study the dynamic temperature and determine the exothermic peak of curing reaction of PF.

4) Fourier Transform Infrared Spectroscopy (FT-IR)

A thin layer of cured mixed polymer was analyzed in the mid-infrared by the Thermo Nicolet Nexus infrared spectrometer at room temperature using a scanning range of $400 \sim 4000 \mathrm{~cm}^{-1}$. The goal was to investigate the modification effects of the silane coupling agent $\mathrm{KH}-550$ on the surface of nano $\mathrm{Al}_{2} \mathrm{O}_{3}$.

5) Field emission scanning electron microscopy (FESEM)

A German FESEM ULTRA PLUS-43-13 was used to observe the dispersion of nano $\mathrm{Al}_{2} \mathrm{O}_{3}$ in the resin both before and after being modified by $\mathrm{KH}-550$ and the interface effect.

\section{RESULTS AND DISCUSSION}

A. The Laser particle size analysis of nano $\mathrm{Al}_{2} \mathrm{O}_{3}$

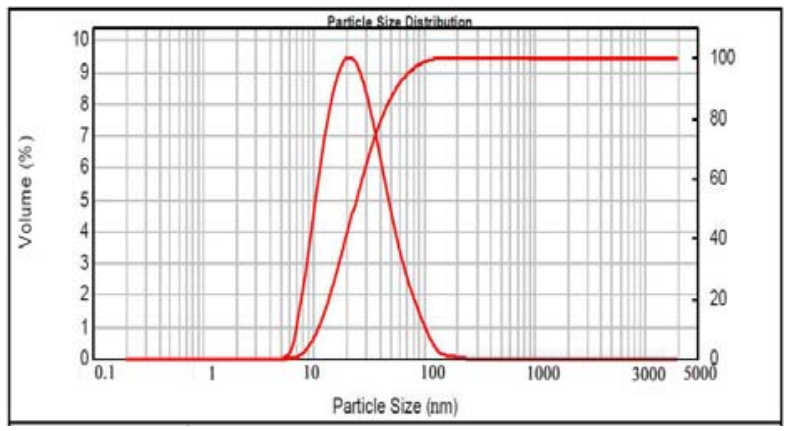

Figure 1. The particle size distribution of nano $\mathrm{Al}_{2} \mathrm{O}_{3}$
Figure 1 shows that the particle size of nano $\mathrm{Al}_{2} \mathrm{O}_{3}$ is mainly distributing in $50 \mathrm{~nm}$. Due to special properties of nanomaterials, such as small size effect, surface effect, quantum size effect and so on. nano $\mathrm{Al}_{2} \mathrm{O}_{3}$ has excellent heat resistance, and it can improve the fireproof performance of the PF.

\section{B. The TG test of the pure PF and silicon-modified PF}

From Figure 2, it is clear that with the increase in silicone resin content (from $5 \%$ to $15 \%$ ), the weight loss of the modified resin gradually decreased. This is due to the addition of the organic silicone resin, which contains a Si-O bond. The bond energy of Si-O is about $472.5 \mathrm{~kJ} / \mathrm{mol}$ and is higher than the $\mathrm{C}-\mathrm{O}$ bond $(432.0 \mathrm{~kJ} / \mathrm{mol})$ and $\mathrm{C}-\mathrm{C}$ bond $(345.6 \mathrm{~kJ} / \mathrm{mol})$. With that high bond energy, the bond on the molecular chain of the resin cannot be easily broken yielding better resistance to heat. However, compared with the $15 \%$ silicon resin modified $\mathrm{PF}$, the final residual carbon rate of the $20 \%$ silicon resin modified PF is lower, which is due to the hydrolysis of a large amount of silicon resin. Some $\mathrm{Si}-\mathrm{O}-\mathrm{Si}$ bonds are easily ruptured decreasing resistance.

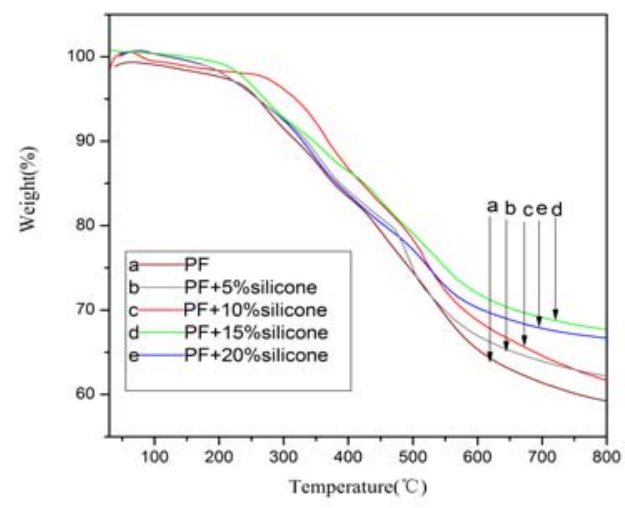

Figure 2. The TG cures of Pure PF and silicone blending modified PF

TABLE I THE RELATIONSHIP BETWEEN THE RESIDUAL RATE AND TEMPERATURE OF THE FIVE SAMPLES

\begin{tabular}{lllllllll}
\hline $\begin{array}{l}\text { Temperature } \\
/{ }^{\circ} \mathrm{C}\end{array}$ & 100 & 200 & 300 & 400 & 500 & 600 & 700 & 800 \\
\hline $\mathrm{a}(\%)$ & 99.4 & 96.9 & 90.1 & 79.1 & 68.9 & 59.3 & 55.7 & 53.6 \\
& 1 & 2 & 3 & 2 & 7 & 6 & 2 & 0 \\
$\mathrm{~b}(\%)$ & 99.3 & 96.8 & 89.9 & 79.4 & 71.5 & 63.3 & 60.4 & 59.0 \\
& 4 & 7 & 6 & 2 & 9 & 3 & 0 & 1 \\
$\mathrm{c}(\%)$ & 99.4 & 98.0 & 90.3 & 82.7 & 73.8 & 66.4 & 61.9 & 60.2 \\
& 7 & 8 & 2 & 1 & 3 & 0 & 4 & 9 \\
$\mathrm{~d}(\%)$ & 99.6 & 98.3 & 92.8 & 85.5 & 77.5 & 69.3 & 65.7 & 64.8 \\
& 7 & 8 & 6 & 5 & 3 & 2 & 7 & 4 \\
$\mathrm{e}(\%)$ & 99.6 & 98.5 & 96.1 & 86.7 & 78.3 & 68.7 & 64.5 & 61.6 \\
& 9 & 7 & 7 & 4 & 7 & 8 & 9 & 8 \\
\hline
\end{tabular}

From Table I, we can easily see that the final residual carbon rate of $15 \%$ silicone-modified PF system is the highest, which is the best ratio. The silicone modified PF mentioned in the following experiments all used this ratio, and the description is not repeated. 


\section{The DSC and TG test of Pure PF and $15 \%$ silicone blend modified $P F$}

Figure 3 is the DSC diagram of pure PF and modified PF. According to the curve of sample $b$ which is $15 \%$ silicone blend modified PF, there is an exothermic peak at $223.9^{\circ} \mathrm{C}$, which is caused by the oxidation of the methylene in the molecular chain of the PF. It is higher than the exothermic peak of the pure PF. This is because the introduction of the organic silicone resin objectively dilutes the concentration of free phenol phenolic substrates and reduces the oxidation of phenol hydroxymethylene in the phenolic resin. At the same time, the biggest exothermic peak of pure phenolic resin is at $530.5^{\circ} \mathrm{C}$, which is caused by the fracture of the main chain of the molecule with no other exothermic peaks at higher temperatures.The modified $\mathrm{PF}$ has a small endothermic peak at $712.0^{\circ} \mathrm{C}$ mainly caused by the cracking of the $\mathrm{Si}-\mathrm{O}$ bond in the mixed system that needs to absorb more heat. Visibly, the heat resistance of blending system is improved.

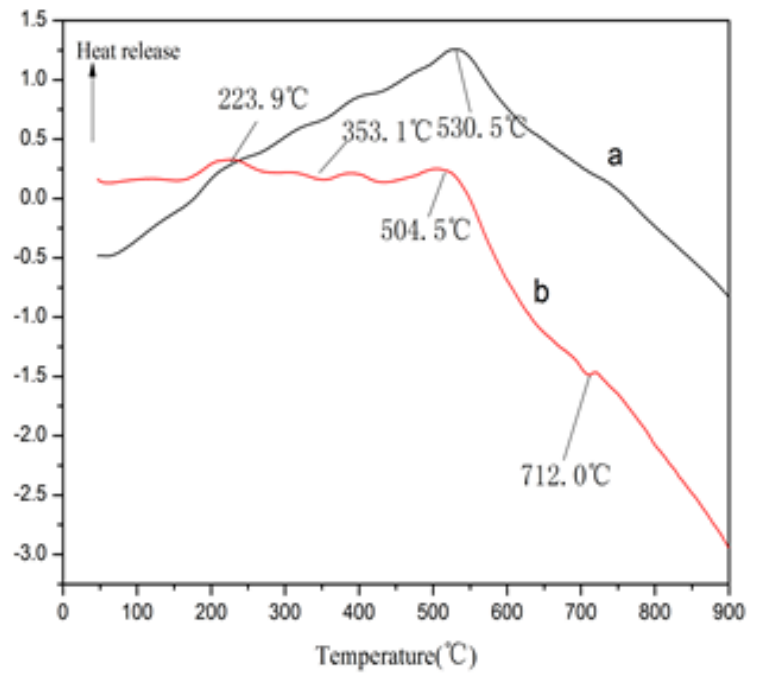

Figure 3. The DSC cures of Pure PF (a) and 15\% silicone blend modified PF (b)

\section{TG characterization of silicon/PF, nano $\mathrm{Al}_{2} \mathrm{O}_{3} / \mathrm{PF}$ and} nano $\mathrm{Al}_{2} \mathrm{O}_{3} /$ silicon $/ \mathrm{PF}$.

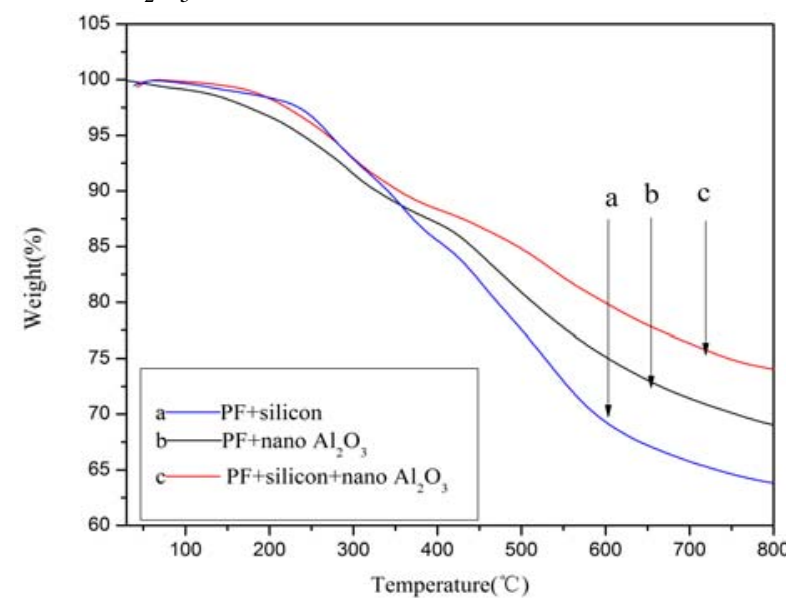

Figure 4. The TG curves of silicon/PF, nano $\mathrm{Al}_{2} \mathrm{O}_{3} / \mathrm{PF}$ and nano $\mathrm{Al}_{2} \mathrm{O}_{3} /$ silicon $/ \mathrm{PF}$.

From Figure 4, as $\mathrm{PF}$ is used to make composite material with silicone resin and nano $\mathrm{Al}_{2} \mathrm{O}_{3}$ separately. The heat resistance of the composite material of nano $\mathrm{Al}_{2} \mathrm{O}_{3} /$ silicone/PF is best and their residual carbon rate reach $78 \%$ at $800^{\circ} \mathrm{C}$. This is followed by nano $\mathrm{Al}_{2} \mathrm{O}_{3} / \mathrm{PF}$. The residual carbon rate of silicone resin $/ \mathrm{PF}$ is the last and reach $64 \%$ at $800^{\circ} \mathrm{C}$. It can be inferred that the heat resistance of pure nano $\mathrm{Al}_{2} \mathrm{O}_{3}$ or pure silicone resin does modify $\mathrm{PF}$, but is imperfect. The nano $\mathrm{Al}_{2} \mathrm{O}_{3} /$ silicon/PF system is much better however. Therefore, the best formula should be nano $\mathrm{Al}_{2} \mathrm{O}_{3}$ and silicone blend-modified $\mathrm{PF}$ together. Because the nanoparticles easily reunite, they need a surface treatment via a coupling agent followed by ultrasonication to ultimately improve the heat resistance of the entire system.

E. The FT - IR characterization of nano Al2O3 modified by the silane-coupling agent.

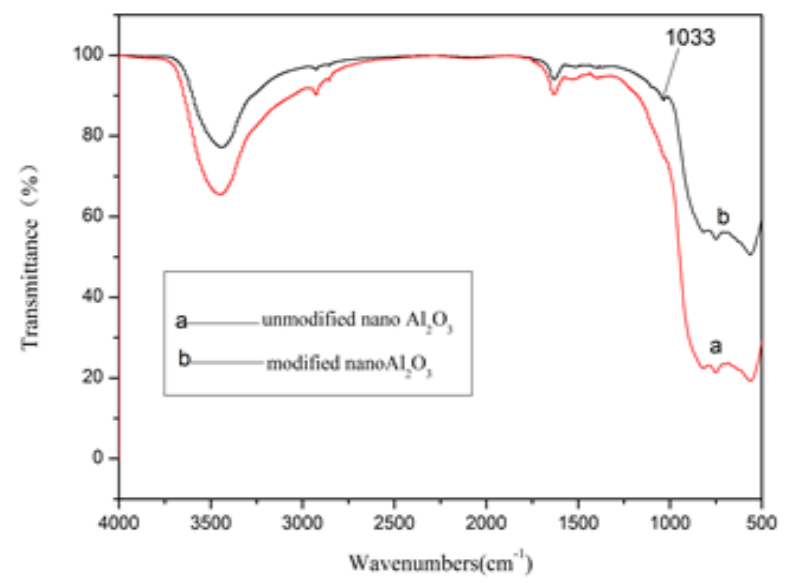

Figure 5. The FTIR curves of unmodified nano $\mathrm{Al}_{2} \mathrm{O}_{3}$ and modified nano $\mathrm{Al}_{2} \mathrm{O}_{3}$ 
From Figure 5, the wide absorption band $500 \sim 1000 \mathrm{~cm}$ -1 is within the scope of the nano $\mathrm{Al}_{2} \mathrm{O}_{3}$ characteristic absorption band. The $1630 \mathrm{~cm}^{-1}$ peak represents the absorption peak of $\alpha-\mathrm{Al}_{2} \mathrm{O}_{3}$. In the wave number range of $500 \sim 800 \mathrm{~cm}^{-1}$, there is a strong absorption band at about $563 \mathrm{~cm}^{-1}$ that corresponds to the vibration absorption of the $\mathrm{Al}-\mathrm{O}$ bond ${ }^{[14]}$. In curve $\mathrm{b}$, the $1033 \mathrm{~cm}^{-1}$ band represents the stretching vibration peak of the $\mathrm{Si}-\mathrm{O}$ bond and is different from the absorption peak of curve a. The results show that there are $\mathrm{Si}-\mathrm{O}$ bonds on the surface of the $\mathrm{Al}_{2} \mathrm{O}_{3}$ nanoparticles, and the silane coupling agent has been grafted or coated on the surface of the $\mathrm{Al}_{2} \mathrm{O}_{3}$ particles.

\section{F. The SEM of nano Al2O3 before and after being modified} by $\mathrm{KH}-550$

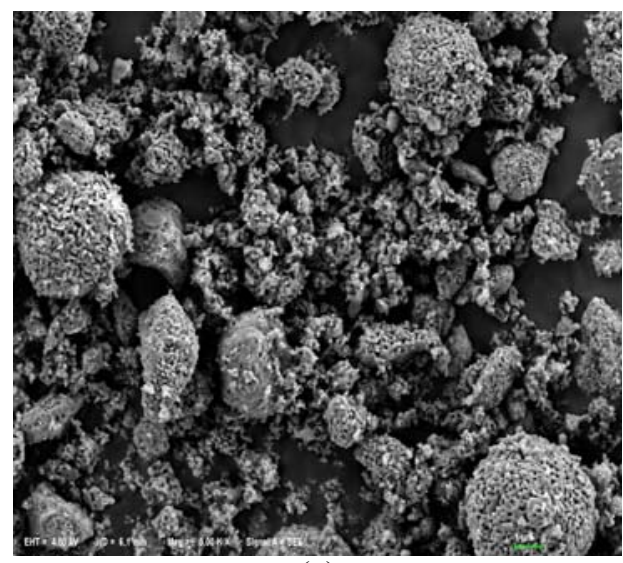

(a)

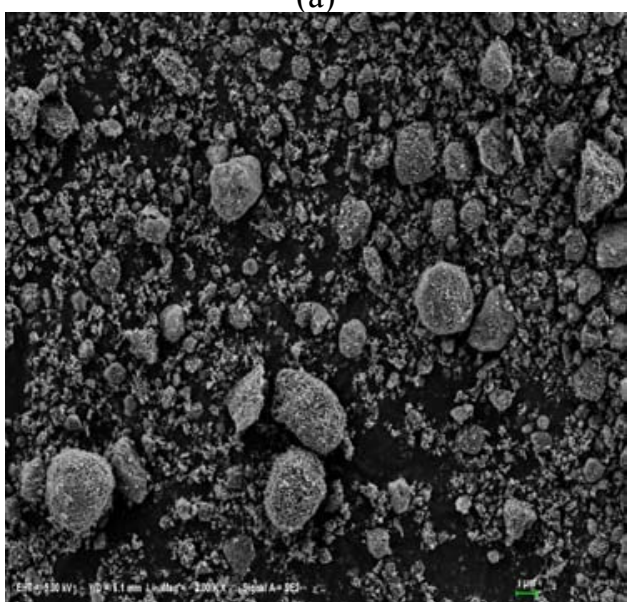

(b)

Figure 6. (a) Unmodified nano $\mathrm{Al}_{2} \mathrm{O}_{3}$ (a) and nano $\mathrm{Al}_{2} \mathrm{O}_{3}$ modified by $\mathrm{KH}-$ 550

In Figure 6, despite a small amount of aggregation of about $2 \mu \mathrm{m}$ particles, the modified nano $\mathrm{Al}_{2} \mathrm{O}_{3}$ particles are more evenly dispersed then unmodified ones. Versus unmodified $\mathrm{Al}_{2} \mathrm{O}_{3}$, the modified one has smaller particle sizes upon reunion. This shows that the nano $\mathrm{Al}_{2} \mathrm{O}_{3}$ modified by silane coupling agent can reacts with PF more effectively and leads to closer integration. The coupling agent $\mathrm{KH}-550$ in the original hybrid system plays a role of molecular bridge - it effectively improves the crosslinking density of the hybrid resin. Eventually, the heat resistance of the modified one is improved.

\section{G. The TG characterization of nano Al2O3/silicon/PF and} modified nano Al2O3/silicon/PF

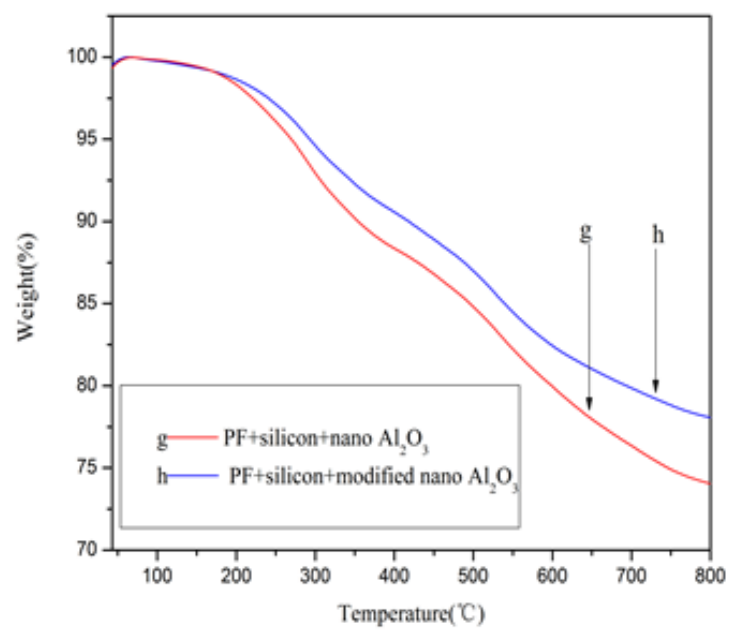

Figure 7. The TG curves of nano $\mathrm{Al}_{2} \mathrm{O}_{3} /$ silicon/PF and modified nano $\mathrm{Al}_{2} \mathrm{O}_{3} /$ silicon/PF

TABLE II THE RELATIONSHIP BETWEEN RESIDUAL RATE AND TEMPERATURE OF THE SAMPLES

\begin{tabular}{lllllllll}
\hline $\begin{array}{l}\text { Temperature } \\
/{ }^{\circ} \mathrm{C}\end{array}$ & 100 & 200 & 300 & 400 & 500 & 600 & 700 & 800 \\
\hline $\mathrm{g}(\%)$ & 99.8 & 98.3 & 92.9 & 88.3 & 84.8 & 79.9 & 76.3 & 74.0 \\
& 3 & 3 & 3 & 6 & 1 & 6 & 6 & 4 \\
$\mathrm{~h}(\%)$ & 99.7 & 98.6 & 94.6 & 90.5 & 86.9 & 82.4 & 79.8 & 78.0 \\
\hline
\end{tabular}

From Figure 7 and Table II, we can knoe the relationship between weight loss and temperature within the two samples. When the temperature reaches $800^{\circ} \mathrm{C}$, the residual rate of the unmodified nano $\mathrm{Al}_{2} \mathrm{O}_{3}$ / silicone/PF is $74.04 \%$, while the modified nano $\mathrm{Al}_{2} \mathrm{O}_{3} /$ silicone/PF is about $78.07 \%$. Therefore, it is clear that the modified nano $\mathrm{Al}_{2} \mathrm{O}_{3}$ can decrease the weight loss of the whole system, and at the same time increase it by about $4 \%$ of the residual carbon rate. That is, the modification of the $\mathrm{Al}_{2} \mathrm{O}_{3}$ can obviously increase the decomposition temperature of the blending resin. In summary, the nano $\mathrm{Al}_{2} \mathrm{O}_{3}$ modified by $\mathrm{KH}-550$ can improve the high temperature resistance of the entire system.

\section{CONCLUSIONS}

As demonstrated by TG analysis, the thermal performance can be improved by PF blending with organic silicone resin. When the temperature reaches $800^{\circ} \mathrm{C}$, the carbon residue rate is above $64.84 \%$, and the initial decomposition temperature (temperature of mass loss of $5 \%$ ) also increased. By the TG analysis and DSC analysis, nano $\mathrm{Al}_{2} \mathrm{O}_{3}$ can improve the heat resistance of the composite materials. At $800^{\circ} \mathrm{C}$, the final weight loss of the whole is decreased by nearly $10 \%$. This effect is quite obvious. As 
demonstrated by IR analysis and SEM analysis this experimental method can graft the silane coupling agent $\mathrm{KH}$ - 550 to cover the surface of the nanoparticles for modification. The modified nano $\mathrm{Al}_{2} \mathrm{O}_{3}$ can effectively reduce the reunion phenomenon and effectively improve the interface bonding ability of nano $\mathrm{Al}_{2} \mathrm{O}_{3}$ and phenolic resin.

\section{REFERENCES}

[1] Nair, C. P. Advances in addition-cure phenolic resins[J]. Progress in Polymer Science 2004,29(5) : 401-498.

[2] Trindade W G, Hoareau W, Megiatto J D,et a1.Thermoset phenolic matrices reinforced with unmodified and surface-grated furfuryl alcohol sugar cane bagasse and curaua fibers:properties of fibers and composites[J]. Biomacromolecules, 2005,6:2485-2496.

[3] Poppe D. Special Ceramics[M]. New York:Academic press, New York, 1965:87.

[4] Mansouri J, Burford R P, Cheng Y B, et al. Formation of strong ceramified ash from silicone-based compositions[J].Journal of Materials Science 2005, 40:5741-5749.

[5] Mansouri J, Burford R P, Cheng Y B. Pyrolysis behaviour of silicone-based ceramifying composites[J]. Materials Science and Engineering: A, 2006, 425(1/2):7-14.

[6] Mansouri J, Wood A, Roberts K, et a1. Investigation of the ceramifying process of modified silicone-silicate compositions[J]. Mater
Sci , 2007, 42:6046-6055.

[7] Hanu L G, Simon G P, Cheng Y B. Thermal stability and flammability of silicone polymer composites[J]. Polymer Degradation and Stability,2006, 91(6):1373-1379.

[8] Hanu L G, Simon G P, Mansouri J, et a1. Development of polymer-ceramic composites for improved fire resistance[J]. Journal of Materials Processing Technology,2004,153-154:401-407.

[9] Alexander G, Cheng Y, Burford R P, et al.Fire-resistant silicone polymer compositions[P].US: 7652090,2010-1-26.

[10] Hermansson A, Hjertberg T,Sultan B-A. The flame retardant mechanism of polyolefins modified with chalk and silicone elastomer[J]. Fire Mater.,2003,27:5 1-70.

[11] Siska Hamdani-Devarennes,AudreyPommier, Claire Longuet,et a1. Calcium and aluminium-based fillers as flame-retardant additives in silicone matrices II. Analyses on composite residues from an industrial-based pyrolysis test[J]. Polymer Degradation and Stability .2011,96:1562-1572.

[12] Buch R R. Rates of H eat Release and Related Fir e Parameters for Silicones [J] . Fire Safety Journal, 1991, 17(1):1-12.

[13] Hsieh F Y, Buch R R. Controlled Atmosphere Cone Caorimeter Studies of Silicones [J]. Fire and Materials,1997, 21( 6):265-270.

[14] Wu J T, Qi S H, Li C H,etc. The preparation and research of environment-friendly phenolic resin modified by $\mathrm{Al}_{2} \mathrm{O}_{3}[\mathrm{~J}]$. China adhesives, 2010,19 (8):39-42. 